\title{
The Counterintuitiveness of Supernatural Dreams and Religiosity
}

\author{
Andreas Nordin | ORCID: 0000-0003-4388-1760 \\ Senior Lecturer, Department of Cultural Sciences, University of Gothenburg, \\ Gothenburg, Sweden \\ andreas.nordin@kultvet.gu.se
}

Pär Bjälkebring | ORCID: 0000-0002-4430-4044

Department of Psychology, University of Gothenburg, Gothenburg, Sweden pop-par.bjalkebring@psy.gu.se

\begin{abstract}
One challenge for cognitive, evolutionary and anthropological studies of religion is to offer descriptions and explanatory models of the morphology and functions of supernatural dreaming, and of the religiosity, use of experience, and cultural transmission that are associated with these representations. The anthropological and religious studies literature demonstrates that dreaming, dream experience and narrative are connected with religious ideas and practices in traditional societies. Scholars have even proposed that dreaming is a primary source of religious beliefs and practice (here labelled DPSR theory). Using Barrett's coding system, we measured a high frequency of minimally counterintuitive dream content among Hindu Nepalese, and we aim to quantify (1) the relation between counterintuitive imagery and reported likelihood to communicate dreams in general and to religious experts, (2) the relation between counterintuitive imagery and reported religiosity, and (3) the proclivity to communicate sA dreams among those who are more or less religious. These aims will then be related to the broader topic of (4) possible explanatory value of DPSR theory, or versions thereof, by framing the issue at the level of cultural transmission, religiosity and credibility of religious dream representations in relation to MCI theory. The article mainly draws upon data from ethnographic research among Hindu Nepalese.
\end{abstract}




\section{Keywords}

dreaming - cognition - counterintuition - supernatural agent concept - religiosity

\section{Introduction}

The research literature from anthropology and religious studies demonstrates how dreaming and dreams have served a range of significant functions in traditional societies and in practically every religious tradition throughout history. This literature tends to show that dreaming, dream experience and narratives connect to other religious ideas and practices such as visitations from the dead, prophetic warnings, divine revelations and blessings, conversions, instruments and models for ritual actions (e.g., Bulkeley, 2007, 2008a; D'Andrade, 1961; Doniger \& Bulkeley, 1993; Lincoln, 1935; Jedrej \& Shaw, 1992; Laughlin, 2011; Lohmann, 2003, Mageo, 2003; O’Flaherty, 1986, Tedlock, 1987; Young, 1999). The ethnographic literature also demonstrates the how sacred cultural value tends to be attached to supernatural dreams (Jedrej \& Shaw, 1992; Littlewood, 2004; Peluso, 2004; Renne, 2004) and the significance of such dreams in all the world's religious traditions (Bulkeley, 2007, 2008a, 2009; Doniger \& Bulkeley, 1993). Dreams seem to provide anchors for belief by presenting direct perceptual and experiential evidence of various religious entities and spirit realms (Bulkeley, 2008a). Such convictions relate to intensely emotional dream experiences, a sense of "realness" about dream imagery, and often involuntary and ambiguous encounter with supernatural entities, as evidenced by nightmares, apparitions and "big dreams" (encounters with sAs of significance in the culture) and "visitation dreams" (encounters with the dead, relatives, loved ones and ancestors) that combine an intense sense of reality with a strongly frightening or non-frightening experience. These traits imply a cultural representation or folk belief about dream-realism and dreaming as direct perception of (supernatural) reality (e.g. apparitions, revelations, divine gaze "darshan"). Various scientific or "neurocognitive" stances hold instead that dream contents occurring during REM (NREM) sleep are not perceptual items or part of a perceptual system, but result from the generation of predictions, simulations and modelling by the mind/brain (e.g. Llewellyn, 2016; McNamara 2016; Revonsuo, 2000). One proposition concerning belief in supernatural dream-realism that developed out of early anthropological theorizing is that dreaming provided a primary experiential source of religion; this is known as "DPSR theory" (e.g. Tylor, 1871). The assumption that dreaming has causal "primacy" for religion is 
unwarranted for various reasons. From an anthropological perspective, "religion" is not a unitary phenomenon (e.g., Bloch, 2008; Boyer, 2013; Sperber, 2017) and is better understood as comprising a range of phenomena. Whatever the causes may be behind the manifestation of traits in such a category, they are likely to be complex, plural and probabilistic. A recognition of the "fractionated" condition of this category can serve as a methodological starting point for a kind of "piecemeal" (Barrett, 2007) or "building-blocks" approach to studying religion (Taves, 2011). "Religious dreaming" and dreaming as an important "source of religion" should be understood in a "fractionated" sense. This article assumes that SA cognition and counterintuitiveness make up a set of predominant traits in this fractionated category. Nontrivial connections between dreaming and religious traits undoubtedly exist, and explorations of these links could be labelled "moderate" versions of DPSR theory. Dreams may accordingly be effective means for the cultural transmission and spreading of religious ideas (Knafo \& Glick, 2000). Research on religion, dreaming and allegedly "mystical experiences" demonstrates that REM (NREM) sleep generates religious beliefs such as the existence of supernatural agents or "SA cognitions" (McNamara et al., 2018; McNamara, 2016), and that SA cognition in religious dreaming manifests (minimally) counterintuitive imagery (MCI) (Nordin, 2020; Nordin \& Bjälkebring, 2019). The present article adopts contemporary models in cognitive and evolutionary anthropology and the study of religion to recast some of the notions of DPSR theory by exploring SA cognition, MCI phenomena and theory in relation to "religious dreaming". Using Barrett's coding system to identify minimally counterintuitive content among Hindu Nepalese, we aim to describe the relationship between MCI dream content, religiosity and willingness to communicate dream content.

\section{Research on Dreaming in Anthropology and the Study of Religion}

Edward Tylor (1871) was an early proponent of studying how dreaming and religion relate by observing cross culturally recurrent notion about dreams as experiences of, and communication with souls, spirits, ancestors and gods. Tylor subsequently suggested that dreaming constitutes the experiential foundation for belief in religions and spiritual ideas. Setting aside the grandiosity of Tylor's approach, an ambivalent stance toward the study of dreams in anthropology has been noted (Hollan 2004) in the sense that the interest of dreaming is there but the field lack of a broadly accepted theory of dreaming that would guide comparison and investigations. In practice, anthropologists employ and 
promote "theories" to make sense of ethnographic data and descriptions of dreaming (e.g., Brereton, 2000; Crapanzano, 2003; Groark, 2009; Lohmann, 2007; Mageo, 2003). One trend is to combine psychoanalytical models with various Marxist, postcolonial and critical studies (e.g., Mageo, 2003). Systematic cultural differences in dreaming are addressed according to typologies: about "nonsense"/bizarreness; discernment; semiotic messages; generative precognition; soul travel and visitation themes in dreams (Lohmann, 2007: 41-44). There has been tendency to favour dream discourse over experience and mental events (Crapanzano, 2003; Tedlock, 1987). The emphasis on cultural models highlights the importance of the social communicative context of which the dream and the dreamer are part (Tedlock, 1987), and these public representations are usually structured according to dream classifications about how the dreams are perceived, used and connected to social dynamics and pragmatic concerns (Kilborne, 1987: 174).

The widespread cross-cultural appeal of supernatural dream imagery (Jedrej \& Shaw, 1992; Littlewood, 2004; Peluso, 2004; Renne, 2004) is codified in the world's religious traditions (Doniger \& Bulkeley, 1993; Bulkeley, 2007, 2008a, 2009). Cross-cultural comparisons of ethnographic studies of dreams accentuate the prominence of cultural representations that connect dreams to religious systems by treating dreams as means to contact or gain control of supernatural powers (D'Andrade, 1961: 320, 328). These beliefs relate to notions about the soul travelling during sleep and meeting other souls and spirits; and themes about fear of loneliness, isolation, and demands for self-reliance. It is a widespread cultural belief that the dreamer's "soul" visits a "spirit world" and/ or "communes" with various gods and spirits (e.g., Lohmann, 2003). Dreams and nightmares tend to be employed in local religious practices involving shamans, healers, prophets and oracles in local disciplines and rituals such as cults of pilgrimage, initiations and conversion ordeals (Morinis, 1982; Bulkeley, 2007). Nightmares attract cultural attention and tend to be construed as warnings from various SAs such as spirits, ancestors, God or the gods, or demons.

\section{Sleep States, Neurocognitive Underpinning and Supernatural Dream Imagery}

Only a few dream memories are preserved and conveyed to the waking state, since most are routinely forgotten. Specific types of dreams are memorable enough to be accessible in waking states. Current research indicates that emotions influence many parts of cognition including memory (Slovic et al., 2007); 
consequently emotions elicited in or by dreams are apt to affect whether and how dreams are remembered. Frightening and negative emotions dominate in this respect, and dream studies suggest that $80 \%$ of dreamers' reports refer to these types of experiences (Hall \& Van de Castle, 1966; Revonsuo, 2000; see also McNamara et al., 2015), of which fear is the most frequent, followed by anger and sadness. Other research demonstrates that $6 \circ \%$ of reappearing dreams and nightmares concern natural hazards and attacks by predatory entities and agents (Robbins \& Houshi, 1983).

Dreaming occurs predominantly during REM (rapid eye movement) sleep, yet dreaming goes on more or less all night long (Bulkeley, 2007), including during NREM sleep states (e.g., McNamara \& Bulkeley, 2015). There is a distinct variation between REM and NREM dreams: the former peak with emotions of fright, nightmarish threat scenery, and bizarre imagery, while the latter manifest the opposite tendency (Hall \& Van de Castle, 1966; Revonsuo, 200o; Domhoff, 2003) and the emotional experiences are much stronger in REM than in NREM states (Scarpelli et al., 2019).

The intricate and distinct physiological and neurological processes that occur during REM sleep (e.g. McNamara \& Bulkeley, 2015; Hobson et al., 1998) include deactivation of the dorsolateral prefrontal cortex, the locus coeruleus, and the noradrenergic and serotonergic systems, in addition to activation of the dopaminergic and cholinergic circuits. The co-occurrence of these intricate brain activities during sleep states firmly correlates with higher-level cognitive processes.

For instance, during the REM-sleep dream process, the tendency to generate a self-model shifts or dissolves, causing a sense of involuntariness that leads to other agents and entities in the dream sequence being experienced as the main causal agents (McNamara, 2016; McNamara \& Bulkeley, 2015). Dream sequences can thus generate experiences where other agents, presumably supernatural ones, are perceived as the cause of the dream and the dream events, rather than the dreamer. The connection between frightening/ non-frightening imagery and REM/NREM dream states respectively strongly suggests that the supernatural dream content is heavily affected. And in fact, various forms of aggressive, demonic, predatory and threatening supernatural imagery prevail in REM states, while non-apprehensiveness, friendliness and similar qualities characterize imagery during NREM states (Bulkeley, 2007; Nordin, 2011; McNamara \& Bulkeley, 2015). Supernatural agent imagery is a common feature of nightmares in various cultures and in terrifying lucid dreams, sleep paralysis, nocturnal panic attacks and other psychiatric disorders, all of which frequently arise during REM sleep (e.g. McNamara et al., 2018). 
Dreaming seems to function as a mode of simulation running hypothetical or predicted future events. Counterfactual dream simulation of past and future states has been demonstrated (McNamara et al., 2002) and extends to dreaming as prospective coding (Llewellyn, 2016) and encoding for episodic memories (Llewellyn, 2013), and in daydream contents in relation to episodic prospection (Spuznar, 2010; McNamara \& Bulkeley, 2015). According to "threat simulation theory" (TST) (Revonsuo, 2000; Valli \& Revonsuo, 2007, 2009) the dream machinery and processes seen during REM and even perhaps in NREM sleep are selected and evolved cognitive processes geared to simulating and rehearsing threat perception and threat avoidance skills, in order enhance vigilance in waking life and possibly reproductive fitness. Hence, TST formulates an evolutionary rationale underlying nightmares and leitmotifs about the threats to survival, aggression, misfortune, accidents, or attacks by wild animals, strangers, or monstrous entities that prevail in the majority of dreams (Hall and Van de Castle, 1966; Domhoff, 1996). Other adaptive simulation functions of dreaming have been suggested in relation to fitness pressures from costly social and sexual selection, signalling (McNamara, 2004) and social interaction (Brereton, 2000; cf., Humphrey, 2000: 953-953; Nielsen \& Germain, 2000: 978-979) and for other fitness functions (see, e.g., Franklin \& Zyphur, 2005; cf., Valli \& Revonsuo, 2007; Kahn \& Hobson, 2005). TST further relates to other cognitive proclivities such as a "hypersensitive agency detection device", HADD (Barrett, 2004a,b), see below, and perhaps both TST and HADD are instances of a general tendency of precautionary psychology (Boyer \& Bergstrom, 2008).

TST and HADD imply that "theory of mind" attribution, or ToM (e.g., Leslie, 1995), is pervasive in dreams (Schweickert \& Xi, 2010). ToM attribution plays a crucial role in modelling supernatural agent cognition (McNamara \& Bulkeley, 2015), as well as in many models in the cognitive science of religion (e.g., Lawson, 2001; Barrett, 2004a,b, 2008). However, it is not a sufficient condition for categorizing of religious dreams and sA imagery, since other properties may be crucial, such as a sense of special value and reverence (McNamara \& Bulkeley, 2015), strategically important information of cognitive relevance (Boyer, 2001; Barrett, 2004a,b) or, importantly, peculiar cognitive content such as counterintuitiveness, discussed below. The intricacies and division 
of causal agency is also decisive in SA dreaming (McNamara \& Bulkeley, 2015; McNamara, 2016) in that the experiences and imagery imply a suspended self-model of agency that strongly correlates with the elevated sense of the causal-agentive role attributed to other dream characters (McNamara \& Bulkeley, 2015; McNamara, 2016). According to a predictive coding approach (e.g., Howhy, 2013; Clark, 2016), cognitive brain processing strives to confirm its own prospective states. A mismatch between prediction and actual outcomes would encourage attribution of external causal agency (McNamara \& Bulkeley, 2015). Although these descriptions further underscore the peculiarity of the agency attribution in SA dream imagery, they are unable to explain why supernatural agency would be modelled and be the preferred construct in religious dream episodes, and importantly why the constructs tend to be counterintuitive (below). This account furthermore opens the question of whether everyone's, including non-believers', dreams contain sA images.

\section{Supernatural Agents (sAs) and Minimal Counterintuitiveness (MCI) Theory}

Because SA conceptualization is a pivotal building block of "religious" phenomena, (b) (minimal) counterintuitiveness is a predominant property of SA conceptualization, and counterintuitive SA concepts and imagery are prevalent in (religious) dreaming (see below), a crucial question is: How explanatory and important is counterintuitive SA dream imagery for cultural transmission and religiosity generally and for DPSR theory? The notion of counterintuitiveness was held to refer to the way "religious concepts" (and in particular the SA concept) tend to contradict some of the information people more or less intuitively associate with basic ontological categories (e.g. Boyer 2001: 54-65). The concept of counterintuition and the idea of MCI theory suggests the idea of violations, such as "breaches" and "transfers", of intuitive expectations drawn from evolved cognition about basic ontological categories (e.g., Barrett, 2000, 2004a,b; Boyer, 1994, 2001; Pyysiäinen, 2001; see also Barrett, 2008; Pyysiäinen, 2008). MCI theory thus assumes that human understanding is heavily influenced by intuitive ontologies that are automatically employed in category formation and routine interaction with and comprehension of the environment (e.g., Boyer, 1994, 2001). Such intuitive expectations can include distinctions between and tacit assumptions about properties of entities such as animate and inanimate objects, and persons, animals, plants, artefacts and natural or physical objects. 
MCI theory was developed not to explain religious concepts as a naturally demarcated conceptual domain (e.g., Barrett, 2017), but rather why some slightly counterintuitive concepts form distinct cultural patterns. Minimally counterintuitive concepts, it was found, are recalled better than maximally counterintuitive ones, and are cognitively optimal in cultural transmission and communication (Nyhof \& Barrett, 2001; Boyer \& Ramble, 2001). In this way MCI theory provided a cognitive model for why certain concept prevail, are catchier, seize people's attention, and are more memorable than others in a cultural environment, and one crucial factor of such catchiness seems to reside in their relevance and how well they match our human conceptual systems rather than in the concepts themselves. Once encoded they are easier to retrieve than other intuitive concepts, and the effect of MCI tends to be an increased chance of impacting transmission of idea among young adults and adolescents (Hornbeck \& Barrett, 2013). A narrative embedding of concepts and various contextual expectations seems crucial for the recall of modestly counterintuitive notions (Atran, 2002; Atran and Norenzayan, 2004; Gonce et al., 20o6) and they are appraised according to the contextual setting of which they are a part (Gonce et al., 2006) and context-based models or on content for cultural transmission (Upal, 2010). The impact of such biases on transmission of MCI has been suggested to rely on attentiveness to prestige or related to credibility enhancement display "cred" (Henrich, 20o9; Willard et al., 2016). Research by Porubanova et al. (2014) indicates on the other hand that culturally counter-schematic and unexpected concepts are remembered better than concepts that violate ontological domain expectations. Some scholars also argue that the basic intuitive expectations and ontological domain of MCI theory are dubious or should be seen as referring to culturally counterschematic items (Purzycki \& Willard, 2016).

SA/CI Dreams, Selection into Waking Cultural Transmission and DPSR Theory

We hold that MCI theory prima facie has explanatory value for explaining significant features of supernatural agent dreaming and why these representations unfold in cultural transmission, thus generally constituting the factors explaining the traits at stake in DPSR theory.

The proposals in DPSR theory can be qualified according to (a) the input condition, (e.g. perception, reception and integration) of public supernatural 
representations into the dreamer's conceptual "toolkit" of images employed in the dreaming process. Dream representation is partly inspired by, framed by and bears a strong resemblance with the supernatural representations that prevail in the dreamer's cultural and religious environment (during the waking state). As the data from the present research indicates (below) and (Nordin \& Bjälkebring, 2019), this strongly suggests that such input from the waking state and the religious allusions from dreamers' cultural environment is considerable.

There is also (b) an output condition of counterintuitive supernatural imagery from dreams to memory and to waking cultural transmission and communication. Finally, (c) public representations condition the transmission and communication of supernatural dream items during waking states. Various types of ritualization of dreaming, religious divination, and myth and symbolism are seemingly part of this domain. Contextual validation and transmission biases may support counterintuitive notions. For example, counterintuitive dream narratives co-occur with images and religious prototypes that seem to be self-validating (temples, pilgrimage sites, statues, ritual objects and performances, priests and other religious authorities, social norms and religious taboos).

Regarding (b), DPSR theory minimally suggests that SA and CI dreaming generate, cause or affect "religion" in some unique manner. In this article this proposal is taken to mean a causally unique output from dreaming to cultural transmission and religious conditions during waking states. Is SA dream imagery and cognition better suited to waking consciousness than other content and would this be an important explanation of the prevalence of $s$ a beliefs in the majority of cultural populations (and of religious ideas generally)? The literature has not yet demonstrated that such a selective advantage exists, and as highlighted by McNamara et al. (2018), not only SA but other classes of dream images are transferred to waking consciousness. However, some effect may exist, and all that is needed for SA dream cognition to influence religious beliefs and cognition in the waking state would be that at least some sA dream images are recollected to such an extent that they prime or bias an acceptance of SA cognitions (and other religious belief and cognition) in the waking state (McNamara et al., 2018: 439-440).

sA dream cognition is likely to have a distinct function in emotional memory consolidation and in decontextualization and re-contextualization relating to autobiographic experience of episodes and formation of long-term memories. Arguably, once SA and CI dream imagery is entangled with strong emotions and solidified in the long-term memory, this very fact may elevate its relevance, encouraging and thus selecting for the use and engagement of 
SA concepts in cultural transmission and communication. The importance of emotional memory consolidation in relation to sA dreaming may draw a theoretical rationale from models in the cognitive science of religion that suggest a predisposition to detect and infer agency (HADD) in relation to salient experience, uncertainty and urgency (Barrett, 2004a: 39-40; cf. Guthrie, 1993). Frightening dreams and nightmares charged with negative emotions about existential threats also presuppose a strong experience of urgency. SA concepts with counterintuitive properties in dreams would seem particularly attractive to draw upon, and thus would outcompete other concepts and explanations and be construed as the cause or content of the dream. According to the HADD model, this is because by analogy salient dreams are perceived as communicative signs from, or traces of, other agents (Barrett, 2004a: 36-37). Although the appeal of agent causality in relation to the experience of urgency may be strong, these accounts do not explain why religious dreaming would manifest the counterintuitive properties in the first place.

\section{Specific Aims}

(1) MCI is very common in reported dreams (Nordin \& Bjälkebring, 2019), however, it is possible that people are more likely to communicate MCI dreams and thus also to take part in the dream interview, creating sampling issues. Hence, we aim to quantify the relation between counterintuitive imagery and reported likelihood to communicate dreams in general and to religious experts. If there is no significant difference in the willingness to communicate dreams between those who do and do not report MCI, it is likely that the willingness to communicate MCI content is related to the dream itself, as seemingly implied by MCI theory.

(2) Based on DPSR theory, one ("naïve") prediction is that persons who report MCI content in their dreams may be more religious than those who do not report MCI. We therefore aim to quantify the relation between counterintuitive imagery and religiosity. If religiosity and reporting MCI dream content are related, it would make a case for the idea that MCI dreams and religiosity have a strong connection.

(3) Based on the assumption that MCI content has an advantage in cultural transmission and the instigation of religious representations, and to test any possible explanatory value of DPSR theory or moderate version of it, we frame the topic at the level of cultural transmission, religiosity and credibility of religious dream representations in relation to MCI theory. We aim to quantify the proclivity to communicate sA dreams in those who are more or less religious. 
This would indicate that there is a link between religiosity and the communication and interpretation of dreams and dream content, which in turn would support the idea that dreaming is strongly interconnected with the cultural transmission of religious themes and credibility of religious dream representations in certain cultures.

\section{Setting, Method and Results}

The article draws upon interviews from ethnographic research in Nepal in 2016 that aimed to explore and map the modalities of dreaming and occurrence of allegedly counterintuitive dream imagery. In particular, the commonalities of CI in relation to a more general cross-cultural base rates was in focus. The study included Hindu-Nepali informants from the Pokhara and Kathmandu valleys at religious sites and nonreligious sites. Informants were randomly selected and interviewed about the specific content of dreams narratives that they considered to be and remembered as "special". The study consisted of 61 interviews with 39 male $(63.9 \%)$ and 22 female $(36.1 \%)$ subjects. The interviews used a Qualtrics questionnaire that took approximately two hours to complete and covered a variety of topics relating to dream content, social use, emotionality scores, religiosity scores and dream rationalizations. The data discussed here demonstrate (1) the prevalence of counterintuitive sA dream imagery, and that such imagery is framed in episodes drawing information from the input of (2) experience and information present in the waking state that (3) is recognizable from the mundane cultural environment and/or from stipulated items of mythological, religious and moral significance.

The method used in this study followed two steps. Firstly, the assumed modalities of counterintuitiveness in allegedly "religious" dream reports were quantified. This undertaking is in itself of great value for anthropologi$\mathrm{cal}$ and cognitive research on religious and cultural material because it maps base-rates for counterintuition and dreaming (Nordin \& Bjälkebring, 2019). Secondly the social and cultural "importance" of such counterintuitive dream imagery was measured and correlated to a social usability and religiosity scale that indirectly could give us a picture of whether and in what way dreaming can serve as a source of religion, as suggested by D PSR models. In order to measure counterintuitiveness in supernatural dream imagery, Barrett's coding and quantifying scheme for counterintuitiveness - henceforth Barrett's CI scheme (Barrett, 2008) - was employed. Although Barrett's CI scheme was primarily developed for cultural and religious representations in the waking state, the unprecedented layout and rigour of this procedure was a prima facie reason to 
adapt it to dream reports. For a detailed exposition of the steps in this scheme, see Barrett (2008), for its application to folktales, see Barrett et al. (2009) and for its use with supernatural dream imagery, see (Nordin \& Bjälkebring, 2019) and (Nordin, 2020).

The Hindu Nepali informants indicated the presence of counterintuitive properties in their dreams by means of phrases like: "Bhagwan appeared as a half statue (Murti)/half man offering advice"; "Bhagwan appeared as a statue talking to me like a human"; "a big snake (Nag) appeared whispering" (quotes from (Nordin, 2020)).

The dream narratives in the study often contained one counterintuitive item and in some cases more. The longer example below (from Nordin, 2020) demonstrates one counterintuitive transfer of animacy to an artefact or object (bus) coded as ${ }^{\mathbf{A} A r t e f a c t}$ from the underscored section in the quote:

I was going back ... home (Bihar) on a long bus with my other villagers. At the bus stop all the people got [off] ... and I was sleeping. After some time, someone came to the driver's seat ${ }^{1}$ and took the bus to the sky by driving into the air (flying)...(and) the bus stopped at Sworga (heaven) there were many Bhagwans (deities), but I couldn't remember their faces. It was a different world. All were sitting like a single family, reading books, chanting mantras (sacred syllables). I went to the corner, listened and watched them curiously. At the same time the place was full of light and I felt like I had fallen [out of] ... bed and got up screaming on my bed. My wife got up and gave me a glass of water.

The use of Barrett's CI scheme with the ethnographic case of Hindu-Nepali supernatural dream imagery yielded results such as high intercoder reliability $(95 \%)$ regarding the general occurrence of $\mathrm{CI}$ items, high frequency of dreams with at least one CI element $(87 \%)$ in $5^{2}$ of the 6o dream reports, high frequency of dream items with counterintuition about agents (47 out of 57 ), and a few cases (10 out of 57 ) consisting of counterintuitive objects with non-agent properties (more details in (Nordin \& Bjälkebring, 2019)). Although these are limited and culturally specific results, they indicate that counterintuitive objects are relatively common in dreams, at least in certain types of cultural environments. Alternatively, it may be the case that people remember or are inclined to communicate counterintuitive dreams more than dreams without

1 A note about a transcription error: the phrase "driver's seat" replaces the incoherent transcription "driver seated". 
counterintuitive objects, which would also result in a high frequency of dreams with counterintuitive objects being reported.

11

\section{Measures}

The second step of the study was to connect and correlate the reported modalities of counterintuitiveness in the SA dreams with communication about SA and scales of "religiosity" among the dreamers.

\subsection{Proclivity to Communicate Dreams}

Two procedures for measuring communicative proclivity were used. The first dealt with the general topic of whether dreams generally were communicated: "It is important to tell others about your dreams." This was answered on a scale from 1 (Strongly disagree) to 6 (Strongly Agree). The second was a "Have you ever had a dream that you told to a dream expert (priest, bramin, astrologist, dami-jankri, mata, baba)."

\subsection{Religiosity}

The immense literature on religiosity (e.g. Hill \& Hood, 1999; Cutting \& Walsh, 2008; Mathur, 2012) contains various methodological and conceptual challenges, for example, should single or multi-dimensional constructs be employed in characterizing how religious someone is? The present study employs seemingly uncontroversial religiosity traits such as affiliation, activity and behaviour, cognition and beliefs (cf., Hill \& Hood, 1999). More to the point, these components were measured according to subcategories such as eagerness to communicate religious information, and amount of time spent thinking about: (a) SAs, ritual conduct, sacred/moral order and religious experts; (b) belief in the existence of SAs; (c) belief that sAs influence personal welfare; (d) sacredness and sAs; (e) importance and truth value of scriptures and religious experts; (f) frequency of temple attendance, praying, ritual practices; (g) beliefs in ritual efficacy; (h) emotionality, raptures and happiness in religious performances. The religiosity measure items were answered on scales of various length, such as 1 to 6 (see Appendix).

\section{2 \\ Results}

To answer (1), that is, quantifying the proclivity to communicate SA dreams both among those who reported MCI as well as those who are more or less 
religious, we used Spearman's rho correlation. For the first item, "It is important to tell others about your dreams", we found that, those who reported MCI were not more likely to say it is important to tell others about your dreams, $r_{s}=$ $.03, \mathrm{p}=\mathrm{n} . \mathrm{s}$. With the second item, about whether the informant has communicated a dream to a dream expert, we found no significant correlation between reporting an MCI dream and the likelihood of saying that you had communicated a dream to an expert, $r_{s}=.4, \mathrm{p}=\mathrm{n}$.s. This suggests that those who reported MCI dreams did not differ in how they communicated their dreams generally or to experts, compared to those who did not report MCI dreams. This supports the notion that MCI might be more common in dreams than previously thought, at least in the cultural setting of this study.

To quantify the relation between counterintuitive imagery and reported religiosity (2), we investigated whether those who had an MCI dream were more religious than those who did not report MCI in their dreams. We used an independent sample t-test. The test suggests that there was no difference in religiosity between those who reported an MCI dream and those who did not $\mathrm{t}(49)=.674, \mathrm{p}=\mathrm{n} . \mathrm{s}$. This suggests that religiosity and the likelihood of reporting an MCI dream were unrelated in our sample, and that the topic is much more complicated than initially believed. Further, the results may seem partly bewildering, and do not conform well with the historically stated close connection between dreaming and religion and the central assumptions in DPSR theory. Somewhat comparable results were shown from Bulkeley's sample among American Christians (2008b, 2014), demonstrating that people scoring lowest on religiosity (e.g. attending worship services) recalled religious dreams better than those high in religiosity, who remembered considerably less well. Bulkeley's (2014) study further found that dream content was not considerably different between religious and non-religious respondents, apart from the fact that the former tended to construe dream experiences according to religious values. That dream content and experience matches with religious values was also seen in a variety of ways in our Hindu-Nepalese case.

To investigate aim 3 , the role of religiosity in dream communication, we found that religiosity and the belief that it is important to tell others about having had a dream were unrelated $r_{s}=.08, \mathrm{p}=\mathrm{n}$.s., meaning that those who were more religious were not more likely to agree with the statement that it is important to tell others about your dreams. Secondly, to the question whether they actually have had a dream that they communicated to a dream expert, we found a significant correlation between religiosity and likelihood to communicate the dream to an expert $r_{s}=.41, \mathrm{p}=.018$. This suggests that those who are more religious are in fact more likely to communicate their dreams to experts for interpretation or advice. These seemingly contradictory results suggest that 


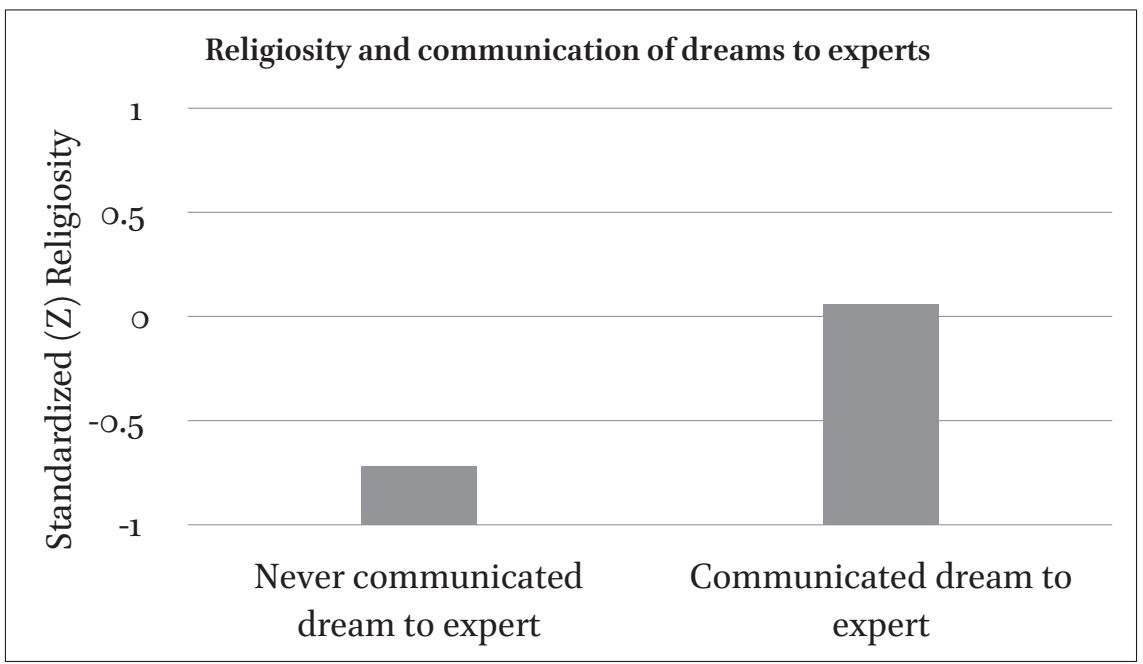

FIGURE 1 The average religiosity of people who reported never having communicated MCI dreams to an expert vs those who did communicate MCI dreams to experts. Zero on the graph constitutes average religiosity. Those who never communicated dreams to experts had lower religiosity, while those who had communicated dreams to an expert had higher religiosity

the second item captures what the informant actually does given the dream experience, rather than confirming an alleged cultural norm about dream sharing. In any case, the present question confirms a correlation between actually having an MCI dream, dream communication and religiosity. Hence, the connection between MCI and religiosity (and possibly DPSR theory) does not lie in the overall communication of MCI dreams, but in the communication of MCI dreams to religious "experts", highlighting the role of dream interpretation in the process of integrating dreams into a religious context.

\section{Discussion and Conclusion}

In the present research sample, counterintuitive SA imagery is prevalent and common in dream reports. This fact strongly supports one understanding of moderate DPSR theory, qualified above as the input condition. It is also important to note that almost all of the dreams reported to us had MCI content, which can mean one of two things for how MCI dreams influence communication. First, if MCI content does not boost the communication of dreams, that would mean that the sample of reported dreams is just a random subset of dreams, and when the participants reported the dreams, they selected 
one random dream of many. However, because MCI items occur in almost all dreams reported in the interviews, that would mean that MCI items occur in almost all dreams. This conclusion is prima facie weak since the literature does not demonstrate the prevalence of MCI items in dreams, (although future research may demonstrate otherwise) and it is at odds with the MCI literature suggesting a transmission advantage of MCI items. If, however, MCI items boost the communication of dreams, this would suggest that when the participants selected a dream to report they chose a dream with MCI items. Hence a possible conclusion would be that MCI does not occur in all dreams, and MCI items do indeed boost the communication of dreams.

When it comes to aim (1) of the study, those who reported MCI in their dreams did not differ from those who did not in their proclivity to communicate dreams in general or to experts, but it is less likely that the frequency of $\mathrm{MCI}$ in the reported dreams is only due to the fact that the people we found who wanted to talk about their dreams were also those with MCI. This suggests that those in our sample who reported MCI do not differ from those who did not report MCI in their general willingness to report dreams. When it comes to aim (2) of the study, regarding how MCI content is related to the dreamer's religiosity, the findings from our sample indicate that they are unrelated. Those who were religious and those who were not religious at all both had the same likelihood of reporting MCI content in their dreams. Hence, the religious content did not stem from the dreamer's religiosity. The religious themes must be a consequence of broader cultural and religious schemata rather than personal beliefs and practices, much in line with the input condition stated previously. Importantly, regarding aim (3) we found no difference between reporting being more religious and wanting to tell others about one's dreams in general. This means that the person's religiosity was not likely to be the source of wanting to talk about dreams in general or MCI dreams in particular. We further found that those who were more religious did indeed say they had dreams that prompted them to consult with an expert. This final finding is of great interest because it leads us to believe that there is an important connection between religiosity and MCI content in dreams. Dream consultation is in many ways the link between having a personal dream experience and getting the dream interpreted, validated and matched to cultural and religious schema. Dream consultation can be part of a religious practice, making sA dreams an important religious factor in the local belief system. Having a powerful MCI dream might lead someone to seek dream consultation, while the dream itself and the dream consultation might lead someone to become more religious by matching the dream with "theologically correct" validation from experts (cf. "cred" and context factors above, in addition to transmission of MCI). Regarding aim 
(4), assessing the explanatory value of DPSR theory, the results are mixed. By assuming that a correlation between MCI content in dreams and religiosity can be used in assessing the DPSR theory, it is confirmed by the discussed input condition, and the prevalence of $\mathrm{MCI}$ dreams referring information prevalent in the dreamers' cultural environment and in particular religious iconology and mythology. If reported motivation to communicate MCI dreams is indicative of religiosity, then that is not confirmed by the findings for aims (1) and (2), but is strongly supported in part by those for aim (3). In light of the present study and results, further cross-cultural studies and improved theoretical models are called for.

\section{References}

Atran, S. (2002). In gods we trust: The evolutionary landscape of religion. Oxford: Oxford University Press.

Atran, S., \& Norenzayan, A. (2004). Religion's evolutionary landscape: counterintuition, commitment, compassion, communion. Behavioral and Brain Sciences, Vol. 27 (4), 713-73o. doi:10.1017/So140525Xo40oo172.

Barrett, J. L. (2000). Exploring the natural foundations of religion. Trends in Cognitive Sciences, Vol. 4 (1), 29-34.

Barrett, J. L. (2004a). Why would anyone believe in God. Walnut Creek: Altamira Press.

Barrett, J. L. (2004b). Counterfactuality in counterintuitive religious concepts. Behavioral and Brain Sciences, Vol. 27 (6), 731-732. doi: 10.1017/So140525Xo4230175.

Barrett, J. L. (2007). Cognitive science of religion: What is it and why is it? Religion Compass, Vol. 1(6), 768-786. doi.org/10.1111/j.1749-8171.2007.00042.x.

Barrett, J. L. (2008). Coding and quantifying counterintuitiveness in religious concepts: Theoretical and methodological reflections. Method \& Theory in the Study of Religion, Vol. 20 (4), 308-338.

Barrett, J. L. (2017). "Could we advance the science of religion (better) without the concept 'religion'?" Religion, Brain \& Behavior, Vol. 7 (4): 282-284. doi.org/10.108o/2153 599X.2016.1249926.

Bloch, M. (2008). Why religion is nothing special but is central. Philosophical Transactions of the Royal Society B: Biological Sciences, Vol. 363 (1499): 2055-2061. doi.org/10.1098/rstb.2008.0007.

Boyer, P. (1994). The naturalness of religious ideas. Berkeley: University of California Press.

Boyer, P. (2001). Religion Explained: The Evolutionary Origins of Religious Thought. New York: Basic Books. 
Boyer, P. (2013). Explaining religious concepts. Lévi-Strauss the brilliant and problematic ancestor. In D. Xygalatas \& W. Jr. McCorkle (Eds.), Mental culture, classical social theory and the cognitive science of religion, (Pp. 164-175). Durham: Acumen Publishing.

Boyer, P., \& Bergstrom, B. (2008). Evolutionary perspective on religion. Annual Review of Anthropology. Vol. 37, 111-130. doi: 10.1146/annurev.anthro.37.081407.085201.

Boyer, P., \& Ramble, C. (2001). Cognitive templates for religious concepts: cross-cultural evidence for recall of counterintuitive representations. Cognitive Science, Vol. 25 (4), 535-564. doi: 10.1207/s15516709cog2504_2.

Brereton, D. P. (2000). Dreaming adaptation, and consciousness: The social mapping hypothesis. Ethos, 28 (3): 379-409.

Bulkeley, K. (2007). Sacred Sleep: Scientific contributions to the study of religious dreaming. In D. Barrett \& P. McNamara (Eds.), The New science of dreaming: Volume 3, Cultural and Theoretical Perspectives, (pp. 71-94). Westport: Praeger.

Bulkeley, K. (2008a). Dreaming in the World's Religions - A Comparative History. New York: New York University Press.

Bulkeley, K. (2008b). American dreamers. Boston: Beacon.

Bulkeley, K. (2009). Mystical Dreaming: Patterns in Form, Content and Meaning. Dreaming, Vol. 19 (1), 30-41.

Bulkeley, K. (2014). Religious Worship and Dream Recall: New Results from a Survey of American Adults. Pastoral Psychol 63, 123-132. https://doi.org/10.1007/s11 o89-013-056o-6.

Clark, A. (2016). Surfing Uncertainty: Prediction, Action and the Embodied Mind. New York: Oxford University Press.

Crapanzano, v. (2003). Concluding Reflections. In J. M. Mageo (Ed.), Dreaming and the Self: New Perspectives on Subjectivity, Identity and Emotion, (pp. 175-197). Albany: University of New York Press.

Cutting, M., \& Walsh, M. (2008). Religiosity Scales: What Are We Measuring in Whom? Archive for the Psychology of Religion Vol. 30 (1), 137-153. https://doi-org.ezproxy .ub.gu.se/10.1163/157361208X317006.

D’Andrade, R. G. (1961). Anthropological Studies of Dreams. In F. L. Hsu (Ed.), Psychological Anthropology: Approaches to Culture and Personality, (pp. 298-332). Homewood: Dorsey Press.

Doniger, W., \& Bulkeley, K. (1993). Why study Dreams? A Religious Studies Perspective. Dreaming, Vol. 3 (1), 69-73.

Domhoff, W. G. (1996). Finding meaning in dreams - A quantitative approach. New York: Plenum.

Domhoff, W. G. (2003). The scientific study of dreams: Neural networks, cognitive development and content analysis. Washington: American Psychological Association.

Franklin, M., \& Zyphur, M. (2005). The Role of Dreams in the Evolution of the Human Mind. Evolutionary Psychology, Vol. 3, 59-78. doi.org/10.1177/147470490500300106. 
Gonce, L., Upal, A., Slone, J., \& Tweney, R. (2006). Role of context in recall of counterintuitive concepts. Journal of Cognition and Culture, Vol. $6\left(3^{-4}\right), 5^{21-547}$. doi: $10.1163 / 156853706778554959$.

Groark, K. P. (2009). Discourses of the Soul: The Negotiation of Personal Agency in Tzotzil Maya Dream Narrative. American Ethnologist, Vol. 36 (4), 705-721.

Guthrie, S. (1993). Faces in the Clouds. New York: Oxford University Press.

Hall, C. S., Van de Castle, R. L. (1966). The Content Analysis of Dreams. New York: Appleton-Century-Croft.

Henrich, J. (2009). The evolution of costly displays, cooperation, and religion: credibility enhancing displays and their implications for cultural evolution. Evolution and Human Behavior, Vol. 30 (4), 244-26o. doi: 10.1016/j.evolhumbehav.2009.03.005.

Hill, P. C., \& Hood, R. W. (1999). Measures of Religiosity. Birmingham, AL: Religious Education Press.

Hobson, J., Pace-Schott, E., Stickgold, R., \& Kahn, D. (1998). To dream or not to dream? Relevant data from new neuroimaging and electrophysiological studies. Current Opinion in Neurobiology, Vol. 8 (2), 239-244. doi: 10.1016/So959-4388(98)80146-3.

Hollan, D. (2004). The Anthropology of Dreaming: Selfscape Dreams. Dreaming, Vol. 14 $(2-3), 170-182$.

Hornbeck, R., and Barrett, J. (2013). Refining and testing "counterintuitiveness" in virtual reality: cross-cultural evidence for recall of counterintuitive representations. The International Journal for the Psychology of Religion. 23 (1), 15-28. doi: 10.1080/10508619.2013.735192.

Howhy, J. (2013). The predictive mind. New York: Oxford University Press.

Humphrey, N. (2000). Dreaming as play. Behavioral and Brain Sciences, Vol. 23 (6), 953. doi: 10.1017/So140525X00504026.

Jedrej, M. C., \& Shaw, R. (1992). Dreaming, Religion and Society in Africa. Leiden: Brill.

Kahn, D., \& Hobson, A. (2005). Theory of mind in dreaming: awareness of feelings and thoughts of others in dreams. Dreaming, Vol. 15 (1), 48-57. doi: 10.1037/ 1053-0797.15.1.48.

Kilborne, B. (1987). On Classifying Dreams. In B. Tedlock. (Ed.) Dreaming: Anthropological and Psychological Interpretation, (pp. 171-193). Cambridge: Cambridge University Press,.

Knafo, A., \& Glick, T. (2000). Genesis Dreams: Using a Private, Psychological Event as a Cultural, Political Declaration. Dreaming, 10 (1), 19-30.

Laughlin, C. D. (2011). Communing with the Gods - Consciousness, Culture and the Dreaming Brain. Brisbane: Daily Grail Publishing.

Lawson, E. T. (2001). Psychological perspective on agency. In J. Andresen (Ed.) Religion in mind-Cognitive perspective on religious belief, ritual, and experience, (pp. 141-172). Cambridge: Cambridge University Press.

Leslie, A. (1995). A theory of agency in Sperber, D., \& Premack, A. J. (Eds.) Causal cognition: A multidisciplinary debate, (pp. 121-149). Oxford: Clarendon Press. 
Lincoln, J. S. (1935). The dream in primitive cultures. Oxford: Cresset Press.

Littlewood, R. (2004). From Elsewhere: Prophetic Visions and Dreams Among the People of the Earth. Dreaming, Vol. 14 (2-3), 94-106.

Llewellyn, S. (2013). Such stuff as dreams are made on? Elaborative encoding, the ancient art of memory, and the hippocampus. Behav. Brain Sci. 36(6), 589-6o7. doi: $10.1017 /$ So140525X12003135.

Llewellyn, S. (2016). Dream to predict? REM dreaming as prospective coding. Frontiers in Psychology, 6, 1-16. doi: 10.3389/fpsyg.2015.01961.

Lohmann, R. I. (2003). Introduction. In R. I. Lohmann (Ed.) Dream Travelers Sleep Experience And Culture In The Western Pacific, (pp. 1-18). New York: Palgrave Macmillan.

Lohmann, R. I. (2007). Dreams and ethnography. In D. Barrett \& P. McNamara (Eds.), The New science of dreaming: Volume 3, Cultural and Theoretical Perspectives, (pp. 35-69). Westport: Praeger.

Mageo, J. M. (2003). Dreaming and the Self: New Perspectives on Subjectivity, Identity, and Emotion. Albany: State University of New York Press.

Mathur, A. (2012). Measurement and meaning of religiosity: A cross-cultural comparison of religiosity and charitable giving. Journal of Targeting, Measurement and Analysis for Marketing Vol. 20 (2), 84-95. doi: 10.1057/jt.2012.6.

McCauley, R., Lawson, T. (2002). Bringing ritual to mind: Psychological foundations of cultural forms. Cambridge: University Press.

McNamara, P. (2004). An evolutionary psychology of sleep and dreams. Westport: Praeger.

McNamara, P. (2016). Dreams and visions - How religious ideas emerge in sleep and dreams. Santa Barbara: Praeger.

McNamara, P., Andresen, J., Arrowood, J., and Messer, G. (2002). Counterfactual cognitive operations in dreams. Dreaming 12(3), 121-133. doi: 10.1023/A:1020181607842.

McNamara, P., Bulkeley, K. (2015). Dreams as a source of supernatural agent concepts. Frontiers in Psychology, Vol. 6 (283), 1-8. doi: 10.3389/fpsyg.2015.00283.

McNamara, P., Minsky, A., Pae, V., Harris, E., Pace-Schott, E., \& Aurbach, S. (2015). Aggression in nightmares and unpleasant dreams and in people reporting recurrent nightmares. Dreaming, 25 (3), 190-205. http://dx.doi.org/10.1037/aoo39273.

McNamara, P., Teed, B., Pae, V., Sebastian, A., \& Chukwumerije, C. (2018). Supernatural agent cognitions in dreams. Journal of Cognition and Culture, Vol. 18 (3-4), 428-450. doi: $10.1163 / 15685373-12340038$.

Mohr, S., Borras, L., Betrisey, C., Pierre-Yves, B., Gilliéron, C., \& Huguelet, P. (2010). Delusions with religious content in patients with psychosis: how they interact with spiritual coping. Psychiatry, Vol. 73 (2), 158-172. doi: 10.1521/psyc.2010.73.2.158.

Morinis, A. E. (1982). "Levels of culture in Hinduism: a case study of dream incubation at a Bengali pilgrimage centre." Contributions to Indian Sociology, Vol. 16 (2), 255-270. 
Nielsen, T. A., \& Germain, A. (2000). Post-traumatic nightmares as dysfunctional state. Behavioral and Brain Sciences, Vol. 23 (6), 978-979. doi: 10.1017/So140525Xoo70402X.

Nordin, A. (2011). Dreaming in religion and pilgrimage: cognitive, evolutionary and cultural perspectives. Religion, Vol. 41 (2), 225-249. doi: 10.1080/0048721X .2011 .553141 .

Nordin, A. (2020). Counterintuitive Supernaturalism as a Building Block of Religious Dream Imagery. In G. Larsson, J. Svensson \& A. Nordin (Eds.), Building Blocks of Religion: Critical Applications and Future Prospects, (pp. 55-70). Equinox: Sheffield.

Nordin, A., \& Bjälkebring, P. (2019). Measuring Counterintuitiveness in Supernatural Agent Dream Imagery. Frontiers in Psychology, Vol 10:1728, 1-15. doi: 10.3389/ fpsyg.2019.01728.

Nyhof, M. and Barrett, J. (2001). Spreading non-natural concepts: the role of intuitive conceptual structures in memory and transmission of cultural materials. Journal of Cognition and Culture. 1(1), 69-100. doi: 10.1163/156853701300063589.

O'Flaherty, W. D. (1986). Dreams, illusion, and other realities. Chicago: University of Chicago Press.

Peluso, D. M. (2004). That which I dream is true: Dream narratives in an Amazonian community. Dreaming, Vol. 14 (2-3), 120-235.

Porubanova, M., Shaw, D., McKay, R., \& Xygalatas, D. (2014). Memory for expectationviolating concepts: the effects of agents and cultural familiarity. PLoS One, Vol. 9 (4), 1-7. doi: 10.1371/journal.pone.oogo684.

Purzycki, B., \& Willard, A. (2016). MCI theory: a critical discussion. Religion, Brain \& Behavior, Vol. 6 (3), 207-274. doi: 10.1080/2153599X.2015.1024915.

Pyysiäinen, I. (2001). How religion works: Towards a new cognitive science of religion. Leiden: Brill.

Pyysiäinen, I. (2008). Supernatural agents: Why we believe in souls, gods, and Buddhas. Oxford: University Press.

Renne, E. P. (2004). Dressing in the Stuff of Dreams: Sacred Dress and Religious Authority in Southwestern Nigeria. Dreaming, 14 (2-3): 120-135.

Revonsuo, A. (2000). The reinterpretation of dreams: an evolutionary hypothesis of the function of dreaming. Behavioral and Brain Sciences, Vol. 23 (6), 877-9o1. doi: 10.1017/So140525Xoooo4015.

Robbins, P. R., \& F. Houshi (1983). Some Observations on Recurrent Dreams. Bulletin of the Menninger Clinic, Vol. 47 (6):262-265.

Scarpelli, S., Bartolacci, C., D’Atri, A., Gorgoni, M., \& De Gennaro, L. (2019). The functional role of dreaming in emotional processes. Frontiers in Psychology, Vol. 10:459. doi: 10.3389/fpsyg.2019.00459.

Schweickert, R., Xi, Z. (2010). Metamorphosed characters in dreams: constraints of conceptual structure and amount of theory of mind. Cognitive Science, Vol. 34 (4), 665-684. doi: 10.1111/j.1551-6709.2009.01082.x. 
Slovic, P., Finucane, M. L., Peters, E., \& MacGregor, D. G. (2007). The affect heuristic. European Journal of Operational Research, Vol. 117 (3), 1333-1352. doi: 10.1016/j .ejor.2005.04.006.

Sperber, Dan. 2017. "Cutting culture at the joints?" Religion Brain \& Behavior,Vol. 8 (4), $42-44$.

Spuznar, K. (2010). Episodic future thought: an emerging concept. Perspectives on Psychological Sciences, Vol 5 (2), 142-162. doi: 10.1177/174569161036235o.

Taves, Ann. 2011. Religious experience reconsidered: A building-block approach to the study of religion and other special things. Princeton: Princeton University Press.

Tedlock, B. (1987). Dreaming: Anthropological and psychological interpretations. Cambridge: Cambridge University Press.

Tylor, E. B. 1871. Primitive Culture. Volume 2. London: John Murray.

Upal, A. (2010). An alternative view of the minimal counterintuitiveness effect. Cognitive Systems Research, Vol. 11 (2), 194-203. doi: 10.1016/j.cogsys.2009.08.003.

Valli, K., \& Revonsuo, A. (2007). Evolutionary psychology approach to dream content. In In D. Barrett \& P. McNamara (Eds.), The New science of dreaming, (pp. 95-116) Westport: Praeger Publishers, Greenwood Press.

Valli, K., \& Revonsuo, A. (2009). The threat simulation theory in light of recent empirical evidence: a review. American Journal of Psychology, Vol. 122 (1), 17-38. PMID: https://psycnet.apa.org/record/20o9-o3881-oo3.

Willard A., Henrich, J., \& Norenzayan, A. (2016). Memory and Belief in the Transmission of Counterintuitive Content. Human Nature, Vol. 27 (3), 221-43. doi: 10.1007/s12110 -016-9259-6.

Young, S. (1999). Dreaming in the lotus. Somerville Wisdom Publications. 